This work is licensed under a Creative Commons Attribution License (CC BY 4.0).

\author{
Research article
}

urn:1sid:zoobank.org:pub:B83ADC8D-9B61-4873-81CA-9A2006096314

\title{
The species of Campodorus Förster, 1869 and a related species (Hymenoptera, Ichneumonidae) from China
}

\author{
Shu-Ping SUN ${ }^{1}$, Tao LI ${ }^{2}$, Mao-Ling SHENG ${ }^{3, *}$ \& Jun LÜ ${ }^{4}$ \\ 1,2,3 General Station of Forest and Grassland Pest Management, National Forestry and Grassland \\ Administration, 58 Huanghe North Street, Shenyang 110034, P.R. China. \\ ${ }^{4}$ Forest Pest Control and Quarantine Station of Kuandian Manzu Autonomous County, \\ Kuandian Liaoning 118200, P.R. China. \\ "Corresponding author: shengmaoling@163.com \\ 1Email:sfzzssp@163.com \\ 2Email: litao200105@163.com \\ ㄴ.Email:kdxlj@163.com \\ ${ }^{1}$ urn:1sid:zoobank.org:author:974C0354-6118-4EA9-890F-EF5ECE8F257A \\ ${ }^{2}$ urn:lsid:zoobank.org:author:AE2C4D7F-6132-4A33-A5EC-04CF541BD80E \\ ${ }^{3}$ urn:1sid:zoobank.org:author:3C0EBDB7-26F7-469B-8DB1-5C7B1C6D9B89 \\ ${ }^{4}$ urn:lsid:zoobank.org:author:D5E7E123-3B35-4CEC-85C8-D315EC51B689
}

\begin{abstract}
Ten species of Campodorus Förster, 1869 are reported from China and five species are new to science: C. albilineatus Sheng, Sun \& Li sp. nov. from Guangxi Zhuang Autonomous Region in the Oriental part of China, C. punctatus Sheng, Sun \& Li sp. nov. and C. rasilis Sheng, Sun \& Li sp. nov. from Beijing, C. shandongicus Sheng, Sun \& Li sp. nov. from Shandong Province and C. truncatus Sheng, Sun \& Li, sp. nov. from Liaoning Province. Three species, C. ciliatus (Holmgren, 1857) and C. dauricus Kasparyan, 2005 collected from Liaoning Province and Mesoleius faciator Kasparyan, 2001 from Beijing, are new records for China. A key to species of Campodorus and a related genus known in China is provided.
\end{abstract}

Keywords. Key, new species, Campodorus, Ctenopelmatinae, taxonomy.

Sun S.-P., Li T., Sheng M.-L. \& Lü J. 2020. The species of Campodorus Förster, 1869 and a related species (Hymenoptera, Ichneumonidae) from China. European Journal of Taxonomy 658: 1-26.

https://doi.org/10.5852/ejt.2020.658

\section{Introduction}

Campodorus Förster, 1869 (Hymenoptera Linnaeus, 1758, Ichneumonidae Latreille, 1802, Ctenopelmatinae Förster, 1869) comprises 138 species (Yu et al. 2016), of which 51 are from the Eastern Palaearctic (25 of them also found in the Western Palaearctic) (Kasparyan 2003, 2005, 2006; Uchida 1935), 99 from the Western Palaearctic (Heinrich 1952; Teunissen 1953; Riedel \& Hansen 2012; Yu et al. 2016) and 14 from the Nearctic Region (Ashmead 1902; Townes \& Townes 1973; Carlson 1979; Jussila 1996, 2006); only a single species is known in the Oriental Region (Kasparyan 1998). No 
species of Campodorus have been recorded in the Australasian or tropical Regions. Prior to the present study, two species have been described from China: Campodorus micropunctatus (Uchida, 1942) and C. variegatus (Jurine, 1807) (Uchida 1942; Sheng \& Sun 2014; Yu et al. 2016).

The Palaearctic species of Campodorus were successively revised and keyed by Kasparyan (2003, 2005, 2006). The Far East species of Russia were keyed by Kasparyan \& Khalaim (2007). Campodorus orientalis Kasparyan, 1998 is the only known Oriental species, collected by R. Malaise in Myanmar (Kasparyan 1998).

There are records of Campodorus reared from 38 host species (Yu et al. 2016). Hosts belong to the sawfly family Tenthredinidae (Thirion et al. 1993; Shaw \& Kasparyan 2003; Kasparyan \& Kopelke 2009), mostly the subfamily Nematinae (Broad et al. 2018). Some reported hosts in the Taxapad database (Yu et al. 2016), belonging to Lepidoptera, are obviously erroneous.

In this paper, ten species are reported from China, including Mesoleius faciator Kasparyan, 2001, a species which is easily confused with Campodorus and was only doubtfully included in Mesoleius by Kasparyan (2001). Five new species are described and a key to all known Chinese Campodorus species is provided.

\section{Material and methods}

\section{Institutional abbreviations}

GSFGPM $=$ General Station of Forest and Grassland Pest Management, National Forestry and Grassland Administration, P.R. China

HUM $=$ Hokkaido University Museum, Sapporo, Japan

$\mathrm{KPMNH}=$ Kanagawa Prefectural Museum of Natural History, Odawara, Japan

NHMUK $=$ Natural History Museum, London, United Kingdom

ZISP $=$ Zoological Institute of the Russian Academy of Sciences, St. Petersburg, Russia

ZSMG $=$ Zoologische Staatssammlung München, Munich, Germany

\section{Specimen collection and rearing}

Rearing parasitoids. The cocoons of sawflies were collected under naturally heavily infested trees and reared in the laboratory at room temperature. The emerged insects were collected daily.

Direct collection. Parasitoid adults were collected with interception traps (IT) (Li et al. 2012) mainly in the natural reserves of China: Beijing, Guangxi, Jilin, Liaoning, Shandong.

Examined material. Some type specimens of Campodorus, deposited in HUM, ZISP and ZSMG, were examined. The photos of the types of Campodorus orientalis Kasparyan, 1998, Cuboscopesis epachthoides Heinrich, 1952, Otlophorus crassitarsus Uchida, 1935 and Trematopygus micropunctatus Uchida, 1942, taken by K. Watanabe (KPMNH), were checked and compared to the new species by the corresponding author.

Images were taken using a Leica M205A stereo microscope with LAS Montage MultiFocus. Morphological terminology is mostly based on Broad (2018 et al.). All examined specimens including holotypes and paratypes are deposited in the Insect Museum, GSFGPM. 


\title{
Results
}

\author{
Class Insecta Linnaeus, 1758 \\ Order Hymenoptera Linnaeus, 1758 \\ Superfamily Ichneumonoidea Latreille, 1802 \\ Family Ichneumonidae Latreille, 1802 \\ Subfamily Ctenopelmatinae Förster, 1869 \\ Tribe Mesoleiini Thomson, 1883
}

Genus Campodorus Förster, 1869

Campodorus Förster, 1869 (1868): 213, type-species: Mesoleius melanogaster Holmgren, 1857.

Diagnosis (Townes 1970; Gauld et al. 1997; Kasparyan 2003)

Apical median portion of clypeus swollen; apical margin usually blunt at midline, sharp laterally, usually projecting as thin lobes. Notaulus usually reaching front edge of mesoscutum. Mesopleuron usually mat or sometimes subpolished, its punctures medium-sized to very fine. Median longitudinal and posterior transverse carinae of propodeum usually complete and strong. Fore wing areolet absent; vein 1cu-a distal to M\&RS. Hind wing vein 1-cu longer than cu-a. Dorsal median carinae of first tergite at least reaching beyond spiracle. Second tergite matt (finely shagreened to scabrous), punctures small to very small, or almost absent.

\section{Key to species of Campodorus known from China}

1. Mesosoma mainly red, at least with large yellow to yellowish brown spots. Hind coxa reddish or

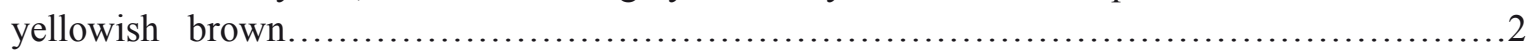

- Mesosoma black or almost entirely black; Hind coxa black or red to yellowish brown.........3

2. Mesoscutum almost shiny, with fine indistinct punctures. Mesoscutum red, except blackish anterior medium spot, mesopleuron red, partly brownish yellow. Face black. Flagellum red brown. In holotype (Transbaikalia) hind tibia white with three blackish rings (basal and subbasal rings weaker).......................................... dauricus Kasparyan, 2005

- Mesoscutum with distinct punctures. Mesoscutum and mesopleuron largely black. Face largely yellow. Flagellum black.

C. variegatus (Jurine, 1807)

3. Median longitudinal carinae of propodeum (Fig. 22) weak or almost absent. Metasomal tergites (Figs 17, 23-25), at least tergites 2-4, reddish brown. Hind coxa and hind femur black, all trochanters whitish (Fig. 17).................................. shandongicus Sheng, Sun \& Li sp. nov.

- Median longitudinal carinae of propodeum complete, strong. Metasomal tergites black, at most posterior margins narrowly white. Hind coxa and hind femur black or reddish brown...........4

4. Propodeum (Fig. 15) with dense long gray-yellow setae, median longitudinal carinae strongly converging medially; anterior to median portion evidently concave. Face (Fig. 12) entirely yellow.

.Mesoleius (?Campodorus) faciator Kasparyan, 2001

- Propodeum without dense long gray-yellow setae, median longitudinal carinae parallel or divergent posteriorly. Face black.

5. Second and subsequent tergites entirely reddish brown. Basal part of hind coxa black, apical part red brown.

C. micropunctatus (Uchida, 1942)

- Second and subsequent tergites black, or only hind margins more or less white. Hind coxa red to reddish brown, or black. 
6. Apex of ovipositor sheath (Fig. 58) almost truncate. Area petiolaris of propodeum (Fig. 56) with more or less distinct median longitudinal carina. Hind coxa black. Basal half of hind tibia buff, apical half black..................................... truncatus Sheng, Sun \& Li sp. nov.

- Apex of ovipositor sheath rounded. Area petiolaris of propodeum without median longitudinal carina. Hind coxa red to reddish brown. Base of hind tibia black, and/or subbasal part more or less bla

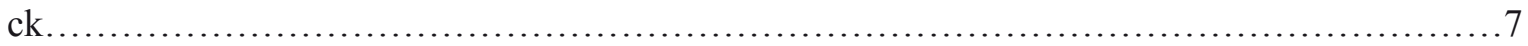

7. Areas superomedia and petiolaris of propodeum (Fig. 49) completely confluent; median longitudinal carinae strongly, evenly divergent posteriorly. Lower lateral portion of face (Fig. 45) with large yellow spots. Metasomal sternites 2-4 buff, sublaterally with longitudinal black spots......................................... rasilis Sheng, Sun \& Li sp. nov.

- Area superomedia and area petiolaris of propodeum separated by strong transverse carina. Face entirely black. Metasomal sternites brownish black, or anterior portion gray white...............8

8. Area basalis and area superomedia of propodeum (Fig. 41) separated by strong transverse carina. Ovipositor sheath $3.0 \times$ as long as maximum width, with dorsomedian portion distinctly widened (Fig. 51).............................................. punctatus Sheng, Sun \& Li sp. nov.

- Area basalis and area superomedia of propodeum completely confluent. Ovipositor sheath at least $3.6 \times$ as long as maximum width, widened subapically (Fig. 10)

9. Median longitudinal carinae of propodeum strongly converging medially. Ovipositor sheath $4.2 \times$ as long as maximum width. Metasomal tergites almost entirely black. At least basal halves of hind basal three tarsomeres white. C. ciliatus (Holmgren, 1857)

- Median longitudinal carinae of propodeum (Fig. 7) almost parallel. Posterior portions of metasomal tergites (Figs 1, 8, 10) with wide white transverse bands. Ovipositor sheath $3.6 \times$ as long as maximum width. Hind tarsomeres entirely black...C. albilineatus Sheng, Sun \& Li sp. nov.

Campodorus albilineatus Sheng, Sun \& Li sp. nov.

urn:1sid:zoobank.org:act:68FEA595-6221-4C58-A1C9-F7F57A917569

Figs $1-10$

\section{Diagnosis}

Clypeus (Fig. 2) approximately $2.2 \times$ as wide as long, shiny, with texture different from face. Speculum large, shiny, smooth (Fig. 6). Metapleuron with texture different from mesopleuron, with dense indistinct punctures. Median longitudinal carinae of propodeum complete, almost parallel. Ovipositor sheath (Fig. 10) approximately $3.6 \times$ as long as its width, evenly widened posteriorly. Hind coxa yellowish white dorsally, brownish red ventrally. Metasomal tergites and sternites 5-6 (Figs 1, 8-10) broadly white on posterior margins.

\section{Differential diagnosis}

The new species is similar to C. ciliatus (Holmgren, 1857), but can be distinguished from the latter by the following combination of characters: median longitudinal carinae of propodeum (Fig. 7) almost parallel; ovipositor sheath (Fig. 10) without particularly long setae; hind coxa yellowish white dorsally, brownish red ventrally; posterior margin of metasomal tergites (Figs 8-10) widely white. Hind tibia pale in basal 0.3, blackish at extreme base and in apical half. Campodorus ciliatus: median longitudinal carinae of propodeum strongly narrowed medially; apical portion of ovipositor sheath at apex with a 
few particularly long setae; hind coxa entirely red; metasomal tergites almost entirely black. Hind tibia predominantly pale rufous, not darkened at base, and brownish in apical 0.33 .

Another Oriental species, C. orientalis Kasparyan, 1998, differs from the new species in having the mesothorax and hind coxa completely red, first flagellomere strongly elongate, $1.9 \times$ as long as second, and areas of the propodeum before the level of the spiracle obliterated.

\section{Etymology}

The specific name is derived from the white bands on the hind margins of the metasomal tergites.

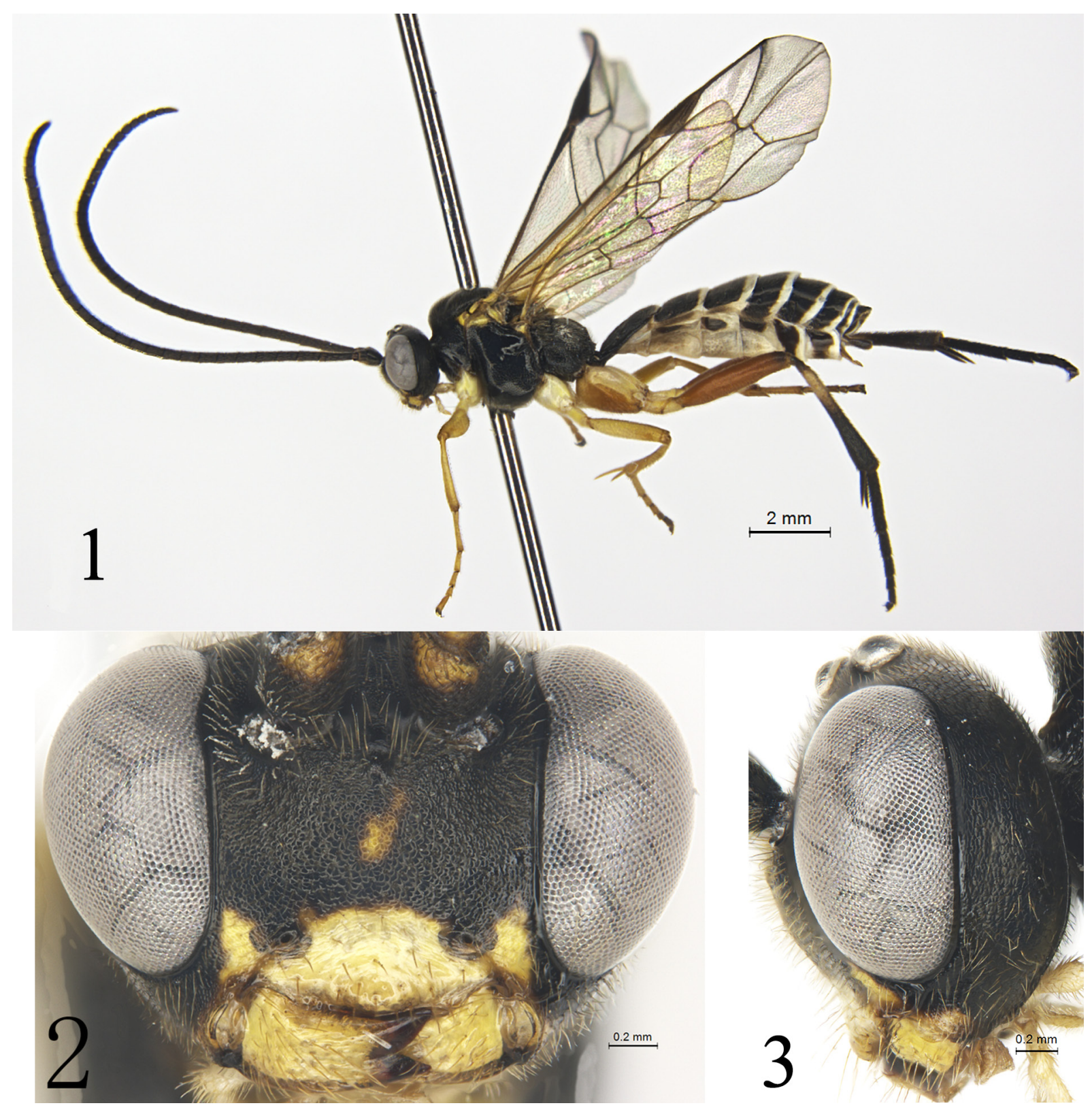

Figs 1-3. Campodorus albilineatus Sheng, Sun \& Li sp. nov., holotype, $q$ (GSFGPM). 1. Habitus, lateral view. 2. Head, anterior view. 3. Head, lateral view. 


\section{Material examined}

Holotype

CHINA - O; Guangxi Zhuang Autonomous Region, Shangsi, Mt Shiwan; 20 Nov. 2018; interception trap; GSFGPM.

\section{Paratypes}

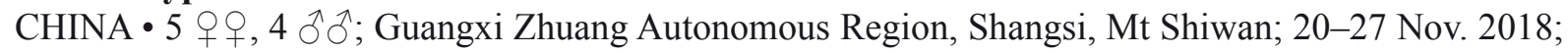
interception trap; GSFGPM.

\section{Description}

\section{Female}

Measurements. Body length 6.9-8.1 mm. Fore wing length 5.5-6.4 mm. Ovipositor sheath length 0.4$0.5 \mathrm{~mm}$.

HEAD. Inner orbits parallel. Face (Fig. 2) approximately $1.7 \times$ as wide as long, shagreened, with shallow indistinct punctures; upper margin with median small tubercle. Clypeus approximately $2.2 \times$ as wide as long, transversely convex, shiny, with sparse yellowish brown setae. Mandible with large shallow sparse punctures and brown setae; upper tooth slightly longer than lower tooth. Malar space slightly shagreened, about $0.4 \times$ as long as basal width of mandible. Gena (Fig. 3) slightly shagreened, hind portion almost shiny, evenly convergent backward. Vertex (Fig. 4) with texture as that of gena, lateral portion with indistinct fine punctures. Postocellar line approximately $0.8 \times$ as long as ocular-ocellar

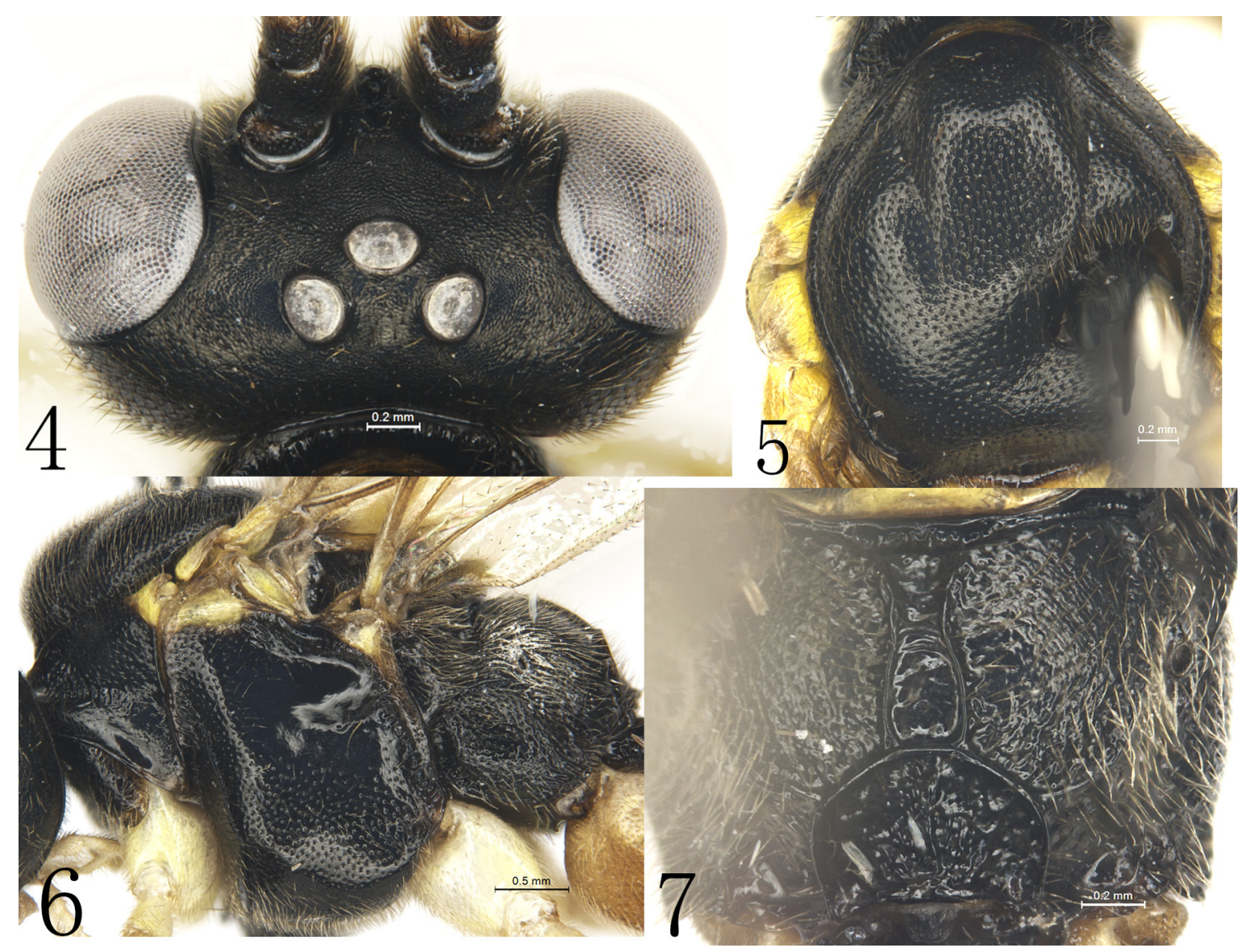

Figs 4-7. Campodorus albilineatus Sheng, Sun \& Li sp. nov., holotype, + (GSFGPM). 4. Head, dorsal view. 5. Mesoscutum. 6. Mesosoma, lateral view. 7. Propodeum. 
line. Frons almost flat, shagreened. Antenna with 33-34 flagellomeres; ratio of length from first to fifth flagellomeres approximately: 1.7:1.1:1.0:1.0:1.0.

Mesosoma. Anterior portion of pronotum (Fig. 6) smooth, shiny; lateral concavity with irregular short transverse wrinkles; upper-posterior portion with distinct, fine punctures. Mesoscutum (Fig. 5) shiny, median portion with relatively dense punctures, distance between punctures $0.5-2.5 \times$ diameter of puncture; sparser on lateral portion, distance between punctures 1.0-4.0 $\times$ diameter of puncture. Notauli distinct in anterior 0.5 of mesoscutum, slightly convergent posteriorly (Fig. 5). Scutellum with dense fine punctures. Postscutellum almost rectangular, with indistinct shallow punctures. Anterior and lower portion of mesopleuron (Fig. 6) smooth with relatively dense punctures, distance between punctures $0.2-$ $2.0 \times$ diameter of puncture; speculum and surrounding area shiny, smooth, without punctures. Upper end of epicnemial carina approximately reaching 0.4 distance to subtegular ridge. Metapleuron with dense indistinct punctures and gray-brown setae (Fig. 6). Claw simple. Ratio of length of hind tarsomeres from first to fifth approximately: 5.2:2.3:1.8:1.0:1.4. Wings slightly brownish, hyaline. Fore wing with vein 1 cu-a distal to M\&RS by approximately $0.5 \times$ length of 1 cu-a. Postnervulus intercepted slightly below middle. Hind wing vein 1-cu 1.5-2.0 $\times$ as long as cu-a. Propodeum (Fig. 7) with irregular indistinct rugae; median longitudinal and posterior transverse carinae complete, strong. Median longitudinal carinae very slightly converging medially, area between them shiny. Posterior half of area petiolaris with irregular longitudinal wrinkles. Propodeal spiracle almost circular.

Metasoma. First tergite (Fig. 8) approximately $1.2 \times$ as long as posterior width, strongly and evenly narrowed to base, slightly shagreened; dorsal median carinae reaching to middle; spiracle small, circular, located approximately at anterior 0.4 of first tergite. Second and subsequent tergites (Figs 8-10) distinctly shagreened, with short brownish gray setae. Second tergite (Fig. 9) approximately $0.6 \times$ as long as apical

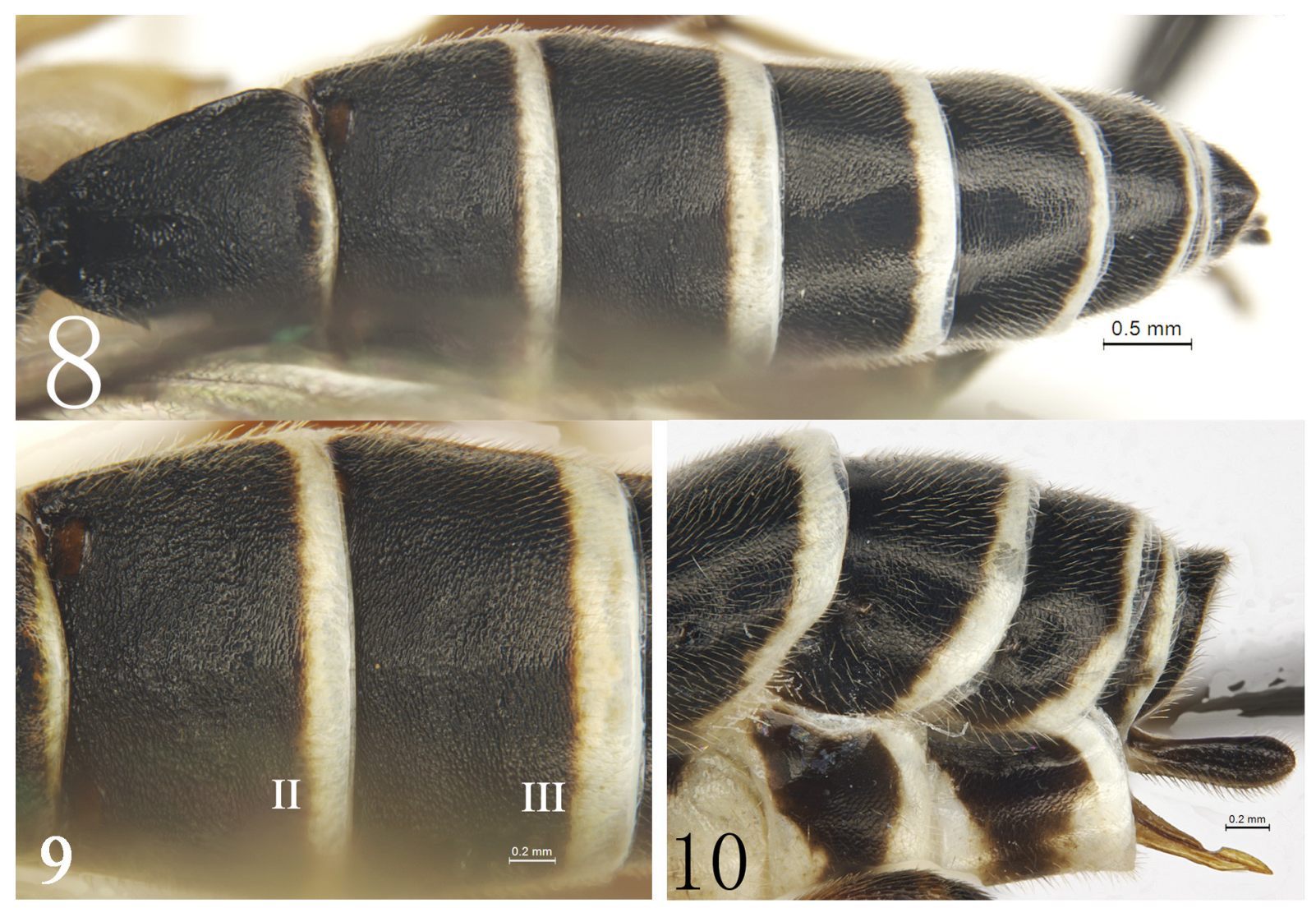

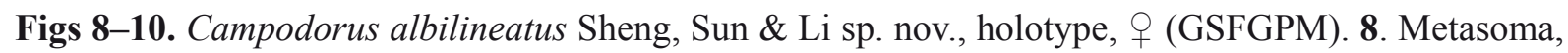
dorsal view. 9. Tergites $2-3$, dorsal view. 10. Apical portion of metasoma, lateral view. 
width. Ovipositor sheath (Fig. 10) approximately $3.6 \times$ as long as its width, evenly widened posteriorly. Ovipositor (Fig. 10) with distinctly wide subapical dorsal notch.

COLORATION (Fig. 1). Black, except for following: apical half of scape ventrally and apical margin of pedicel more or less yellow brown. Clypeus, small median spot and two spots in lower corners of face (Fig. 2), mandible except teeth, maxillary palpi, labial palpi, tegulae, subtegular ridge, scutellum, postscutellum, fore and middle coxae and parts of tarsi, hind coxa dorsally, all trochanters, and subbasal portions of hind tibia whitish yellow. Fore and middle legs except coxae and parts of tarsi brownish yellow. Hind coxa ventrally and hind femur reddish. Posterior portions of metasomal tergites white. Sternites 2-4 broadly whitish in median part, sternites 5 and 6 black with anterior and posterior margins widely white.

\section{Remarks}

Campodorus albilineatus sp. nov. is the only species known from the Oriental part of China.

Campodorus ciliatus (Holmgren, 1857)

\section{Material examined}

CHINA • 1 \%; Liaoning Prov., Shenyang; 23 May 1993; Mao-Ling Sheng leg.; GSFGPM.

\section{Remarks}

New record for China.

\section{Campodorus dauricus Kasparyan, 2005}

\section{Material examined}

CHINA • 1 क; Liaoning Prov., Shenyang; 4 Jun. 1991; Mao-Ling Sheng leg.; GSFGPM • 1 \%; Liaoning Prov., Shenyang; 25 Jun. 1991; Mao-Ling Sheng leg.; GSFGPM.

\section{Remarks}

New record for China.

\section{Mesoleius (?Campodorus) faciator Kasparyan, 2001}

Figs 11-16

\section{Diagnosis}

Head, mesoscutum (Fig. 13), mesopleuron, metasomal tergites 1-3 (Fig. 16) shagreened, almost without punctures. Clypeus approximately $3.3 \times$ as wide as long, smooth, shiny. Lateral portion of propodeum (Fig. 15) with long whitish yellow setae; median longitudinal carinae strongly converge medially. Face and clypeus whitish yellow. Metasomal tergites almost entirely black.

\section{Differential diagnosis}

In main peculiarities of coloration and most other diagnostic characters the Chinese specimens correspond to the holotype of Mesoleius faciator Kasparyan, 2001 (Russia, Chita Prov.), but differ in dense long pubescence of lateral parts of the propodeum; in having more antennal segments (39 flagellomeres) and smaller body size (fore wing $6.6 \mathrm{~mm}$ long); the holotype of M. faciator has 36 flagellomeres and fore wing is $8.1 \mathrm{~mm}$ long. Although described in the genus Mesoleius, Kasparyan (2001) noted that M. faciator occupied an intermediate position between Campodorus and Mesoleius.

\section{Material examined}

CHINA • 1 q; Beijing, Huairou, Labagoumen; 20 Jun. 2011; Bin Tian leg.; GSFGPM. 


\section{Description}

\section{Female}

Measurements. Body length approximately $11.6 \mathrm{~mm}$. Fore wing length approximately $6.8 \mathrm{~mm}$. Ovipositor sheath length approximately $0.4 \mathrm{~mm}$.

HEAD. Face (Fig. 12) approximately $1.8 \times$ as wide as long, shagreened, almost flat, with dense yellowish white setae; upper margin with median small tubercle. Clypeus approximately $3.3 \times$ as wide as long, smooth, shiny, with sparse brown setae; apical margin sharp, subapical portion distinctly convex (Fig. 12). Mandible with sparse indistinct shallow punctures and brown setae; upper tooth slightly wider, longer than lower tooth. Malar area granulated; malar space approximately $0.5 \times$ as long as basal width of mandible. Gena and vertex almost shagreened. Posterior portion of gena distinctly convergent posteriorly. Postocellar line approximately $0.9 \times$ as long as ocular-ocellar line. Antenna with 39 flagellomeres; ratio of length from first to fifth flagellomeres approximately: 1.6:1.3:1.2:1.1:1.0. Occipital carina complete, lower end reaching hypostomal carina distinctly above base of mandible.

Mesosoma. Pronotum (Fig. 14) roughly granulated, lateromedian portion of lateral concavity with fine indistinct oblique wrinkles; subdorsal portion with few distinct oblique wrinkles. Mesoscutum (Fig. 13) and scutellum distinctly shagreened, with sparse fine punctures. Notauli reaching middle of mesoscutum. Scutoscutellar groove smooth. Postscutellum transverse, almost shiny, concave at base. Mesopleuron (Fig. 14) roughly indistinctly shagreened; speculum shiny, smooth; area in front of speculum with fine indistinct punctures. Upper end of epicnemial carina reaching to 0.7 distance to subtegular ridge. Metapleuron (Fig. 14) evenly slightly convex, distinctly shagreened; lower posterior portion with irregular oblique wrinkles. Claw simple. Ratio of length of hind tarsomeres from first to fifth: 4.3:2.1:1.7:1.0:1.4. Wings brownish, hyaline. Fore wing with vein 1 cu-a distal to M\&RS by $0.2 \times$ length of 1cu-a. Postnervulus intercepted below middle. Hind wing vein 1-cu $1.5 \times$ as long as cu-a. Propodeum (Fig. 15) shagreened, lateral portion with long whitish yellow setae; median longitudinal and posterior transverse carinae complete, strong. Median longitudinal carinae strongly narrowed medially, area between them shiny. Area petiolaris shiny, with irregular longitudinal wrinkles. Propodeal spiracle almost circular.

Metasoma. Anterior three metasomal tergites (Fig. 16) shagreened. First tergite $1.4 \times$ as long as posterior width, strongly and evenly tapered to base; posterior margin slightly smooth; dorsal median carina reaching to 0.4 length of first tergite; dorsolateral and ventrolateral carinae complete; spiracle small, circular, slightly convex, located at anterior 0.4 of first tergite. Second tergite (Fig. 16) $0.8 \times$ as long as anterior width, $0.6 \times$ as long as posterior width. Third tergite $0.55 \times$ as long as posterior width, with more or less distinct median transverse depression (Fig. 16). Fourth and subsequent tergites with fine short indistinct transverse rugae. Ovipositor sheath (Fig. 11) about $4.0 \times$ as long as wide, parallel-sided, rounded posteriorly.

Coloration (Fig. 11). Black, except for following: antennae darkish brown dorsally, brown ventrally. Face, clypeus whitish yellow; mandible except teeth, maxillary palpi, labial palpi, malar area, upperposterior corners of pronotum, tegulae, subtegular ridge, posterior margins of tergites 3-7 slightly yellowish white. Fore and middle coxae, except for black bases, their trochanters, apex of hind coxa and hind trochanters ventrally yellow. All femora red to brown red. Fore and middle tibiae and tarsi almost evenly yellowish. Basal 0.6 of hind tibia mainly yellow. Pterostigma and veins black brown. Sternites 2-5 whitish yellow, sublateral parts broadly black (Fig. 11).

\section{Remarks}

New record for China. 


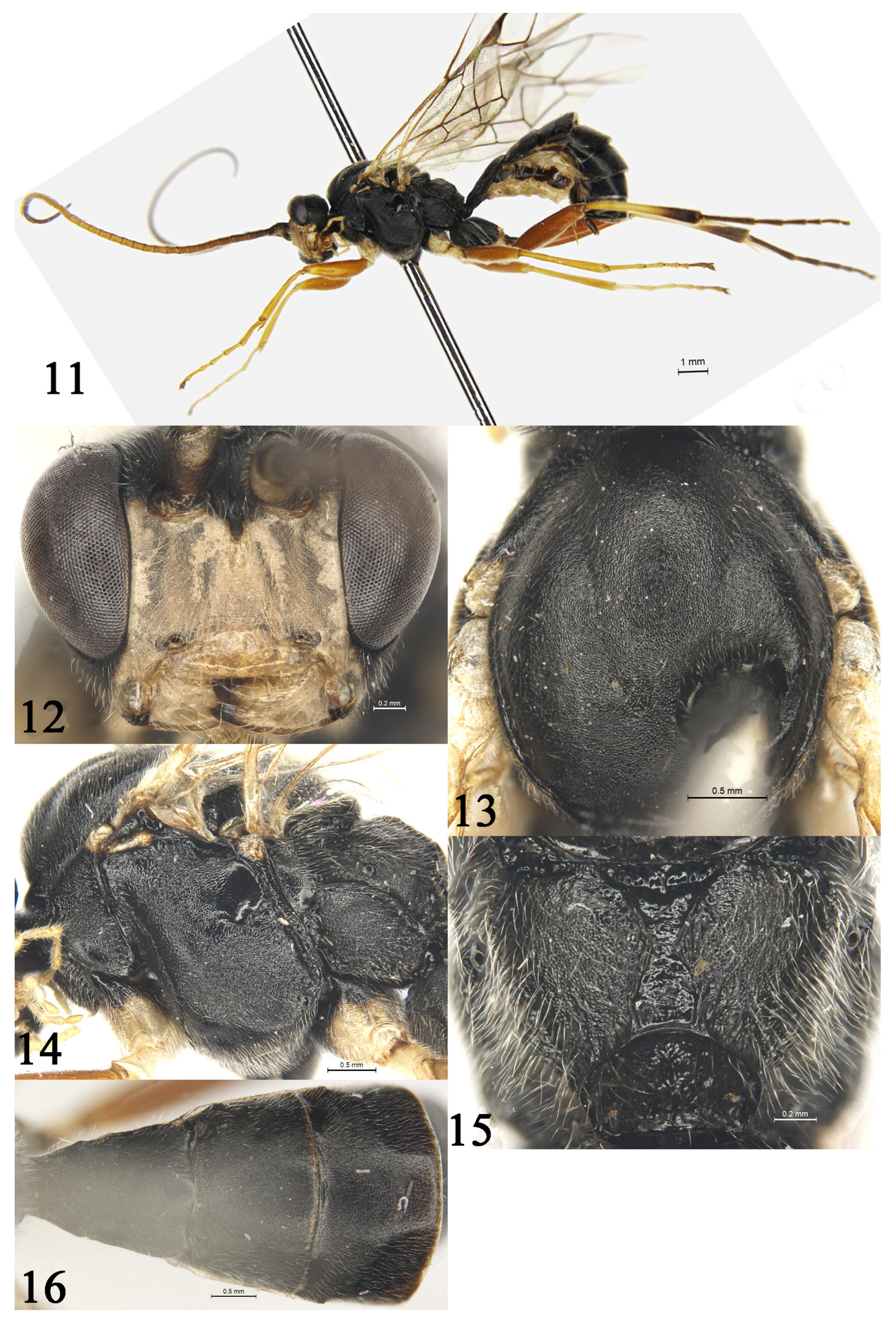

Figs 11-16. Mesoleius (?Campodorus) faciator Kasparyan, 2001, q (GSFGPM). 11. Habitus, lateral view. 12. Head, anterior view. 13. Mesoscutum. 14. Mesosoma, lateral view. 15. Propodeum. 16. Tergites $1-3$, dorsal view. 
Campodorus shandongicus Sheng, Sun \& Li sp. nov. urn:1sid:zoobank.org:act:ADD7B307-1FE4-4A13-855D-6D0E280EE252

Figs 17-25

\section{Diagnosis}

The new species may easily be distinguished from most other congeners in coloration (Fig. 17): by the combination of an almost entirely brownish red metasoma, blackish hind femur and hind coxa, and whitish yellow hind trochanter and a broad ring on the hind tibia. Face (Fig. 18) flat, with dense fine punctures, distance between punctures $0.2-0.5 \times$ diameter of puncture. Upper tooth of mandible slightly shorter than lower tooth. Median longitudinal carinae and median portion of posterior transverse carina of propodeum weak or almost absent. Metasomal tergites shagreened. Ovipositor sheath (Figs 17, 25) approximately $4.2 \times$ as long as its median width, dorsal and ventral margins almost parallel.

\section{Differential diagnosis}

The new species is similar to C. micropunctatus (Uchida, 1942), but can be distinguished from the latter by the following combinations of characters: median longitudinal carinae of propodeum weak (male) or indistinct (female). Ovipositor sheath $4.5 \times$ as long as maximum width. Flagellum brownish black ventrally, black dorsally. Hind femur black. Campodorus micropunctatus: median longitudinal carinae of propodeum distinct and strong. Ovipositor sheath $1.9 \times$ as long as maximum width. Flagellum and hind femur reddish brown.

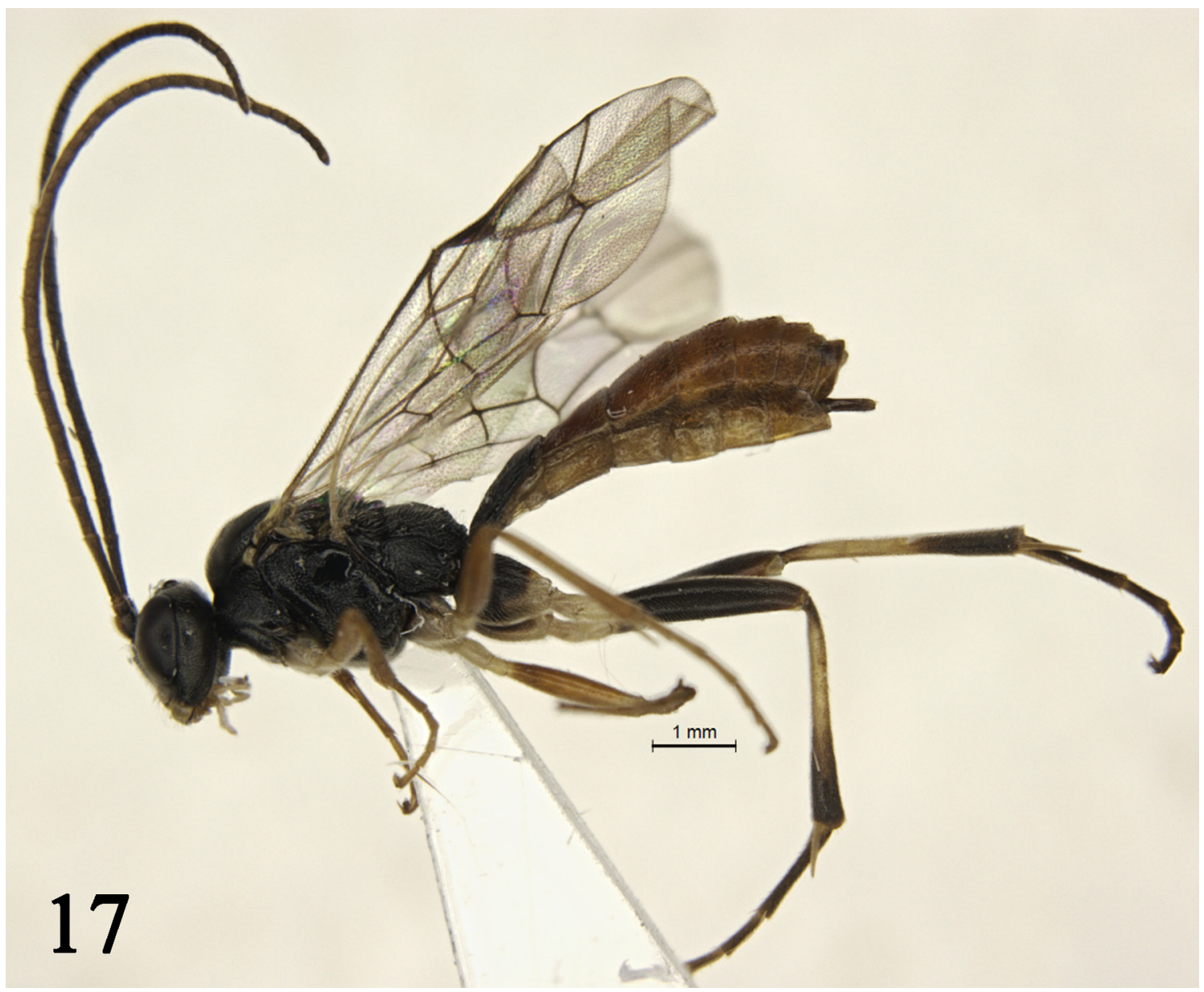

Fig. 17. Campodorus shandongicus Sheng, Sun \& Li sp. nov., holotype, + , habitus, lateral view (GSFGPM). 


\section{Etymology}

The specific name is derived from the type locality.

\section{Material examined}

\section{Holotype}

CHINA - + ; Shandong Province, Qingdao, Laoshan Forest Farm; 26 Jun. 2017; interception trap; GSFGPM.

\section{Paratypes}

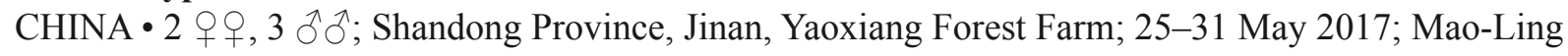
Sheng leg.; GSFGPM.

\section{Description}

\section{Female}

MEASUREMENTS. Body length approximately $5.5 \mathrm{~mm}$. Fore wing length approximately $4.5 \mathrm{~mm}$. Ovipositor sheath length approximately $0.7 \mathrm{~mm}$.

HEAD. Face (Fig. 18) approximately $1.9 \times$ as wide as long, almost flat, with dense fine punctures and fine short setae, distance between punctures $0.2-0.5 \times$ diameter of puncture; upper margin with median V-shaped emargination and small tubercle. Clypeus approximately $2.7 \times$ as wide as long, smooth, shiny; apical median portion distinctly convex, with indistinct shallow punctures. Mandible with shallow sparse punctures and yellow setae; upper tooth slightly shorter than lower tooth. Malar space shagreened, $0.7 \times$ as long as basal width of mandible. Gena (Fig. 19) finely shagreened, with shallow fine punctures. Vertex and frons with texture as that of gena. Postocellar line approximately $0.8 \times$ as long as ocularocellar line. Frons flat. Antenna with 31 flagellomeres; ratio of length from first to fifth flagellomeres approximately: 2.7:1.6:1.5:1.5:1.3. Occipital carina complete, lower end reaching hypostomal carina distinctly above base of mandible.

Mesosoma. Lower-anterior portion of pronotum (Fig. 21) with fine oblique longitudinal wrinkles; lateral concavity with fine transverse wrinkles; upper-posterior portion shagreened. Mesoscutum (Fig. 20) shagreened, with sparse shallow indistinct punctures, median portion finely irregularly rugose. Anterior 0.3 of notauli present. Scutellum, postscutellum shagreened, with indistinct fine punctures. Mesopleuron (Fig. 21) with dense irregular fine wrinkles; upper-anterior and lower-posterior portions with dense oblique longitudinal wrinkles. Upper end of epicnemial carina approximately reaching to 0.35 height of hind margin of pronotum. Speculum large, shiny, smooth. Metapleuron evenly convex, shagreened, with brownish gray short setae. Basal portion of claw finely pectinate. Ratio of length of hind tarsomeres from first to fifth approximately: 4.7:2.2:1.7:1.0:1.3. Wings slightly brownish, hyaline. Fore wing with vein $1 \mathrm{cu}-\mathrm{a}$ distal to M\&RS approximately by $0.25 \times$ length of $1 \mathrm{cu}-\mathrm{a}$. Postnervulus intercepted almost at middle. Hind wing vein 1 -cu approximately $4.0 \times$ as long as cu-a; final abscissa of CU almost unpigmented. Propodeum (Fig. 22) with dense fine punctures, distance between punctures $0.2-1.0 \times$ diameter of puncture; median longitudinal carinae indistinct or absent; median portion of posterior transverse carina absent; area petiolaris with irregular wrinkles. Propodeal spiracle circular.

Metasoma. Metasomal tergites shagreened. First tergite (Figs 23-25) approximately $1.6 \times$ as long as posterior width, evenly narrowed anteriorly; dorsal median carina weak, reaching beyond spiracle; spiracle convex, located at anterior 0.4 of first tergite. Second tergite (Figs 23-24) approximately $0.7 \times$ as long as apical width. Third and fourth tergites with sparse indistinct fine punctures. Third tergite (Figs 23-24) approximately $0.8 \times$ as long as apical width. Ovipositor sheath (Figs 17,25) rather narrow, in profile parallel-sided, rounded at apex, about $4.2 \times$ as long as its median width. Subapical dorsal notch of ovipositor wide. 

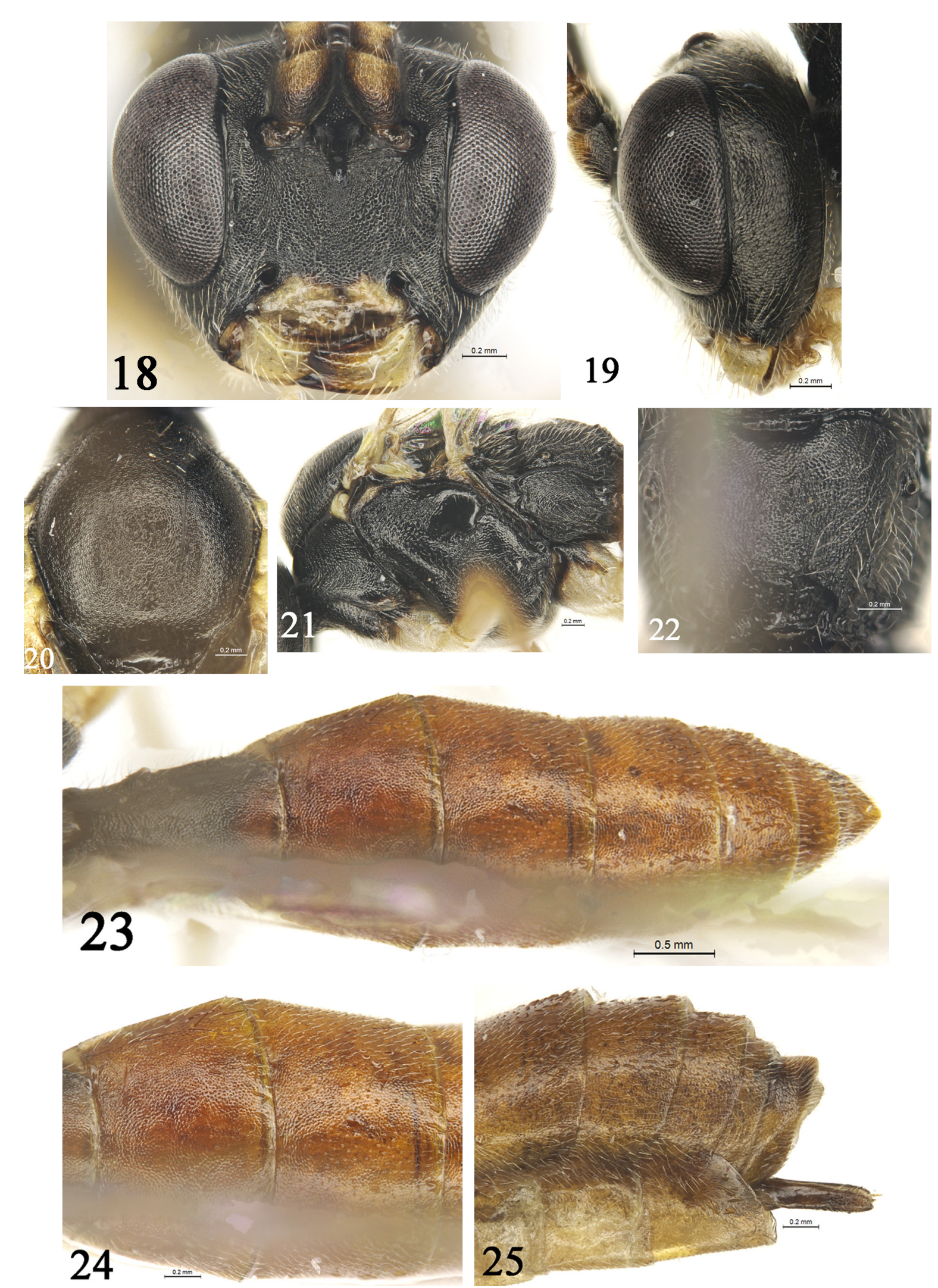

Figs 18-25. Campodorus shandongicus Sheng, Sun \& Li sp. nov., holotype, $q$ (GSFGPM). 18. Head, anterior view. 19. Head, lateral view. 20. Mesoscutum. 21. Mesosoma, lateral view. 22. Propodeum. 23. Metasoma, dorsal view. 24. Tergites $2-3$, dorsal view. 25. Apical portion of metasoma, lateral view. 
Coloration (Fig. 17). Black, except for following: ventral profiles of antennae darkish brown; clypeus, mandible except teeth, maxillary palpi, labial palpi, upper-posterior corner of pronotum, tegulae, subtegular ridge, fore and middle coxae and trochanters, apices of hind coxa, hind trochanter, basal portion of hind tibia except basal ends whitish yellow; remainder of fore and middle legs, posterior portion of first tergite, second and subsequent tergites red brown; pterostigma brownish black; veins black brown. Sternites brownish yellow.

\section{Male}

MEASUREMENTS. Body length approximately $5.8 \mathrm{~mm}$. Fore wing length approximately $4.5 \mathrm{~mm}$.

Body. Face approximately $1.8 \times$ as wide as long, distance between punctures $0.2-1.0 \times$ diameter of puncture. Malar space approximately $0.6 \times$ as long as basal width of mandible. Postocellar line approximately $0.9 \times$ as long as ocular-ocellar line. Antenna with 29 flagellomeres; ratio of length from first to fifth flagellomeres: $2.3: 1.3: 1.2: 1.2: 1.1$. Fore wing with vein $1 \mathrm{cu}-\mathrm{a}$ distal to M\&RS approximately by $0.35 \times$ length of $1 \mathrm{cu}-\mathrm{a}$. Hind wing vein $1-\mathrm{cu} 5.5 \times$ as long as cu-a. Median longitudinal carinae of propodeum weak, complete, very slightly narrowed anteriorly; basal area distinctly concave; area petiolaris with transverse wrinkles. First tergite $2.0 \times$ as long as posterior width; spiracle located at middle of first tergite. Third tergite approximately as long as posterior width.

Coloration. Face yellow, dorso-medially with a small black spot; metasomal fifth and subsequent tergites black. Remainder almost entirely the same as female.

Campodorus micropunctatus (Uchida, 1942)

\section{Material examined}

Holotype

CHINA • 1 \%; Liaoning Prov., Tieling; 11 May 1938; I. Okada leg.; HUM.

Campodorus punctatus Sheng, Sun \& Li sp. nov. urn:lsid:zoobank.org:act:B9653BA7-E1CC-485B-81FF-C10A3ACC5E9E

Figs 26-34

\section{Diagnosis}

Propodeum (Fig. 32) shagreended except shiny areas basalis, superomedia and petiolaris; area basalis separated from area superomedia by strong transverse carina. Area superomedia trapezoidal, almost as long as maximum width. Metasomal tergites (Fig. 33) distinctly shagreened, without punctures. First tergite approximately $1.2 \times$ as long as posterior width. Head except clypeus, mesosoma and metasomal tergites (Figs 33-34) almost entirely black.

\section{Differential diagnosis}

The new species is similar to C. crassitarsus (Uchida, 1935), but can be distinguished from the latter by the following combination of characters: apical half of clypeus with dense large punctures; median longitudinal carinae of propodeum distinctly narrowed medially (Fig. 32); area superomedia and area basalis separated by strong carina; ovipositor sheath (Fig. 34) $3.0 \times$ as long as maximum width, dorsomedian portion distinctly dilated. Campodorus crassitarsus: clypeus almost entirely smooth; median longitudinal carinae of propodeum strongly divergent posteriorly; area superomedia and area basalis confluent (not separated by a carina); ovipositor sheath $2.8 \times$ as long as maximum width, dorsal margin straight, not dilated. 


\section{Etymology}

The specific name is derived from the clypeus with large punctures.

\section{Material examined}

\section{Holotype}

CHINA・ +; Beijing, Mentougou; 22 Aug. 2008; Tao Wang leg.; GSFGPM.

\section{Description}

\section{Female}

MeAsuRements. Body length about $11.3 \mathrm{~mm}$. Fore wing length about $8.7 \mathrm{~mm}$. Ovipositor sheath length $0.7 \mathrm{~mm}$.

HEAD. Inner margins of eyes parallel, distinctly concavenear antennal sockets. Face (Fig. 27) approximately $1.9 \times$ as wide as long, shagreened, median portion with fine indistinct punctures; upper lateral portion slightly concave; upper margin with median small tubercle. Clypeus approximately $2.9 \times$ as wide as long, shiny; its median portion apically strongly convex, with large dense punctures (Fig. 27); median section of apical margin evenly distinctly concave. Mandible with sparse fine punctures and brown setae; upper tooth slightly wider and longer than lower tooth. Malar space shagreened, approximately $0.4 \times$ as long as basal width of mandible. Gena (Fig. 28), vertex (Fig. 29) and frons slightly shagreened, with indistinct fine punctures. Gena evenly convergent posteriorly. Postocellar line approximately $0.6 \times$ as long as ocular-ocellar line. Frons almost flat, shagreened. Antenna with 37 flagellomeres; ratio of length from first to fifth flagellomeres approximately: 1.8:1.2:1.1:1.0:1.0.

Mesosoma. Anterior portion of pronotum (Fig. 31) shagreened; lateral concavity shiny, with short wrinkles; upper-posterior portion shagreened. Mesoscutum (Fig. 30), scutellum and postscutellum shagreened, with shallow sparse indistinct punctures. Scutoscutellar groove almost smooth, shiny. Postscutellum transverse. Mesopleuron (Fig. 31) and metapleuron shagreened, slightly shiny, with fine indistinct punctures. Speculum large, smooth, shiny. Upper end of epicnemial carina approximately reaching to 0.7 distance to subtegular ridge. Metapleuron strongly convex. Ratio of length of hind

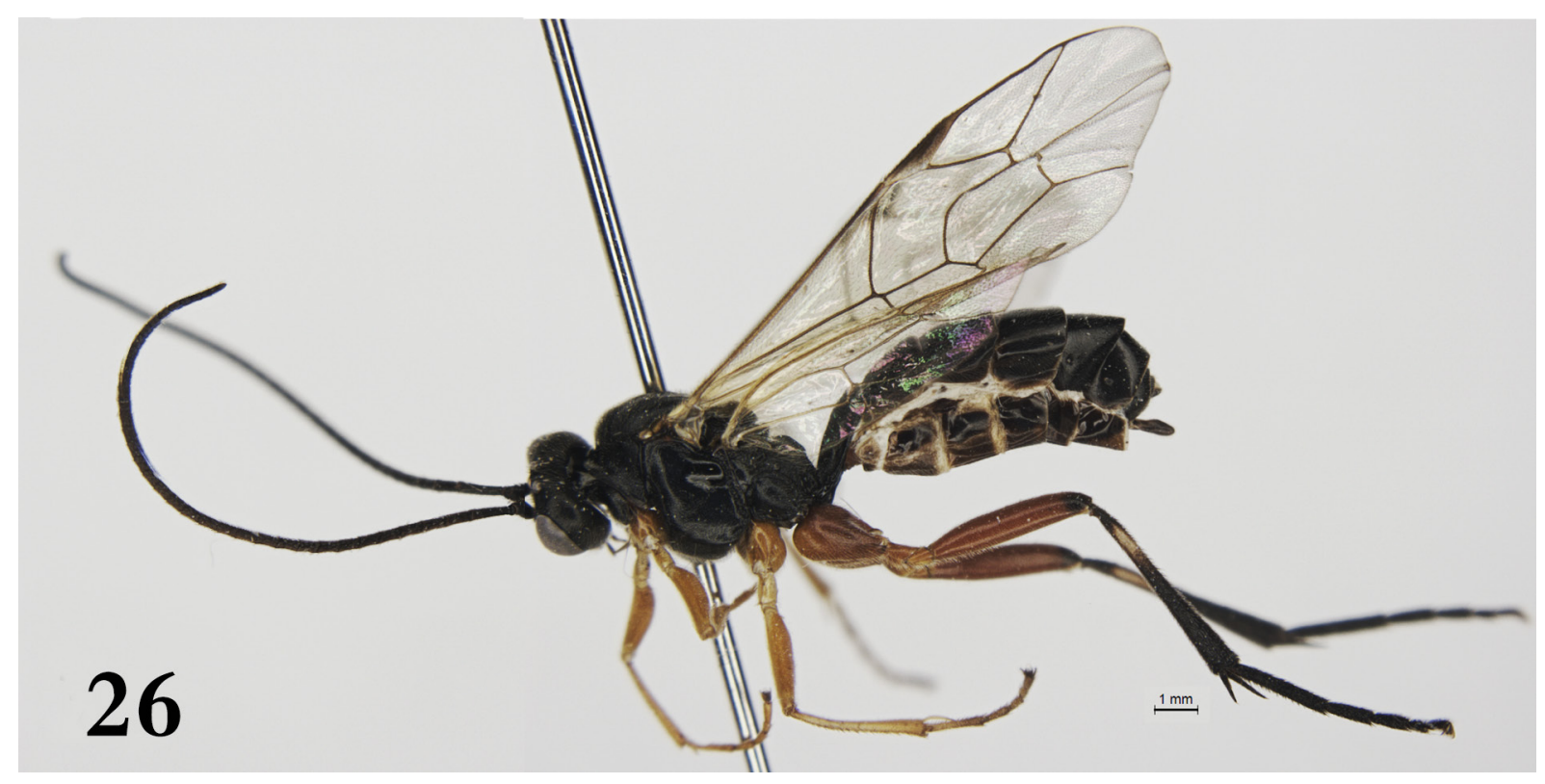

Fig. 26. Campodorus punctatus Sheng, Sun \& Li sp. nov., holotype,, , habitus, lateral view (GSFGPM). 

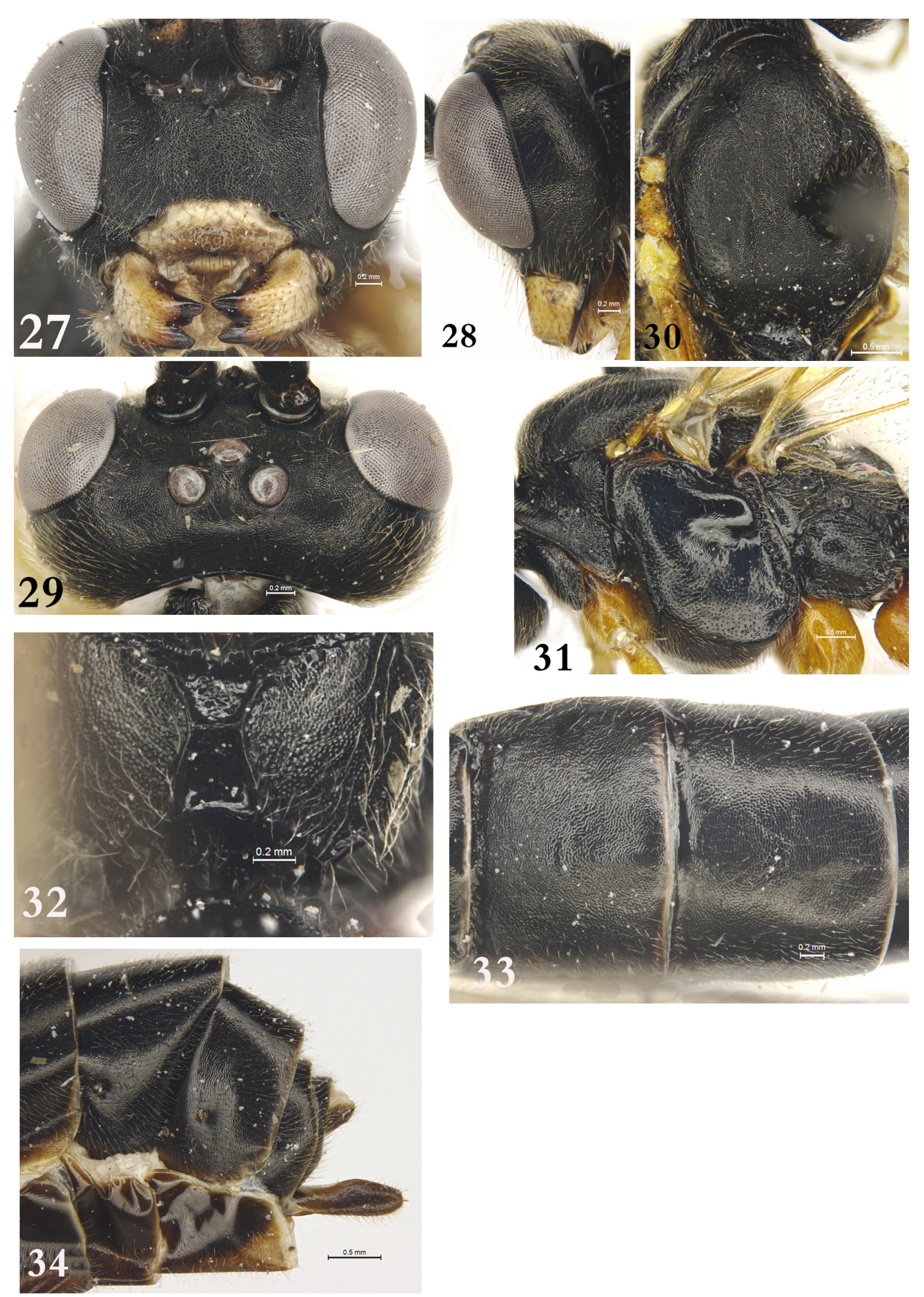

Figs 27-34. Campodorus punctatus Sheng, Sun \& Li sp. nov., holotype, $q$ (GSFGPM). 27. Head, anterior view. 28. Head, lateral view. 29. Head, dorsal view. 30. Mesoscutum. 31. Mesosoma, lateral view. 32. Propodeum. 33. Tergites $2-3$, dorsal view. 34. Apical portion of metasoma, lateral view. 
tarsomeres from first to fifth approximately: 5.1:2.5:1.9:1.0:1.4. Wings slightly gray, hyaline. Fore wing with vein $1 \mathrm{cu}-\mathrm{a}$ distal to M\&RS approximately by $0.4 \times$ length of $1 \mathrm{cu}-\mathrm{a}$. Postnervulus intercepted slightly below middle. Hind wing vein 1-cu slightly longer than cu-a. Propodeum (Fig. 32) shagreened except shiny areas of basalis, superomedia and petiolaris; area basalis separated from area superomedia by strong transverse carina. Area basalis reversed trapezoidal. Area superomedia trapezoidal, almost as long as maximum width. Propodeal spiracle almost circular, located at anterior 0.25.

Metasoma. First two tergites shagreened. First tergite approximately $1.2 \times$ as long as posterior width; dorsal median carina reaching beyond spiracle; spiracle small, circular, located approximately at anterior 0.4 of first tergite. Second tergite (Fig. 33) approximately $0.8 \times$ as long as anterior width, $0.7 \times$ as long as posterior width. Third and subsequent tergites almost shiny, slightly shagreened, with short brownish gray setae. Ovipositor sheath (Fig. 34) approximately $3.0 \times$ as long as its maximum width, from middle narrowed posteriorly. Ovipositor straight, compressed.

COLORATION (Fig. 26). Black, except for following: basal half of clypeus yellow, apical half yellowish brown (Fig. 27); mandible, except teeth, maxillary palpi, labial palpi, tegulae and subbasal spot of hind tibia yellow; fore and middle legs except yellowish trochanters, hind coxae, trochanters and femur except apex brownish red; antennae, pterostigma and veins brownish black. Sternites 1-3 mainly brownish black medially, black laterally. Sternites 4-6 black.

Campodorus rasilis Sheng, Sun \& Li sp. nov.

urn:lsid:zoobank.org:act:29420300-0110-4CD2-9099-F288E2AB8B4D

Figs $35-41$

\section{Diagnosis}

Upper median area of face (Fig. 36) with dense distinct punctures, lateral portion distinctly shagreened. Clypeus smooth, shiny, $3.2 \times$ as wide as long. Hind wing vein 1-cu approximately $4.0 \times$ as long as cu-a. Anterior and posterior transverse carinae of propodeum (Fig. 39) absent. Median longitudinal carinae evenly narrowed anteriorly, area between them smooth, shiny (Fig. 39). Face black, lower-lateral spots yellowish white (Fig. 36). Flagellum brown. Scutellum and postscutellum reddish brown.

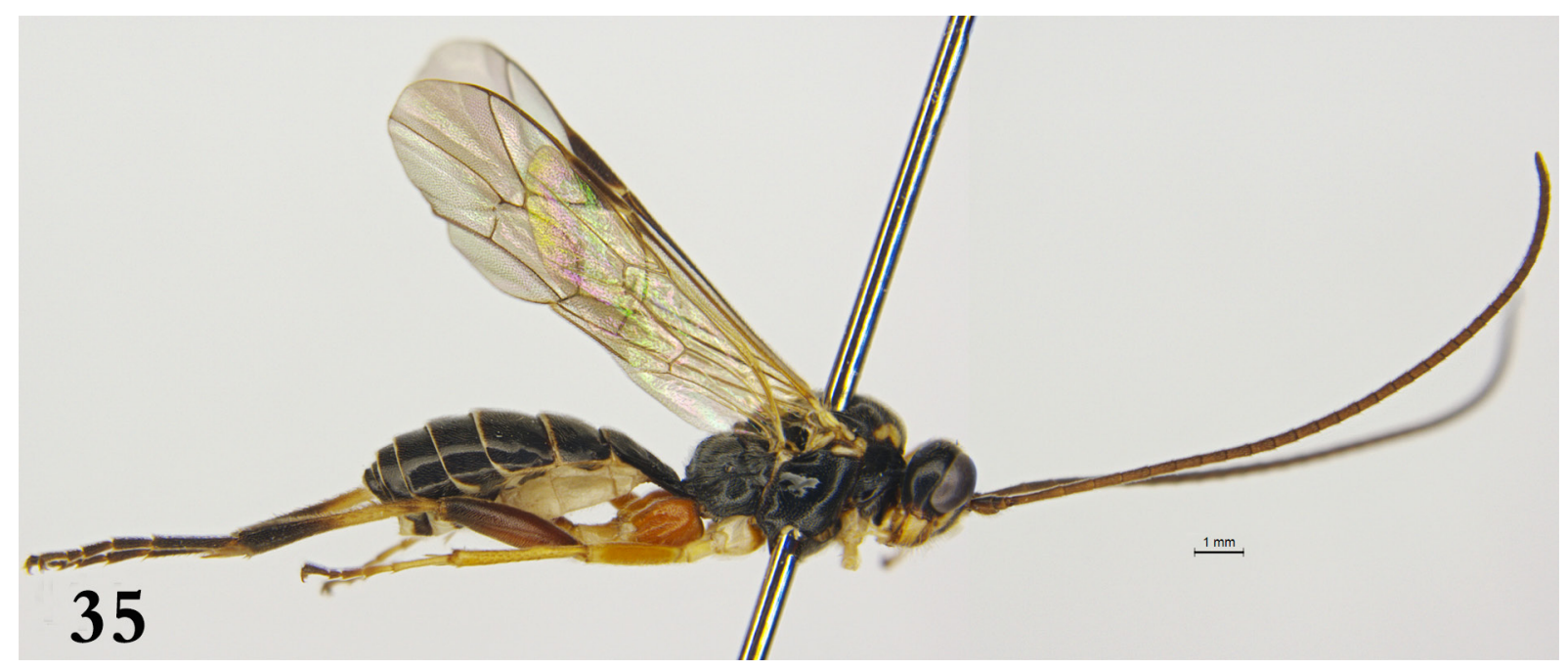

Fig. 35. Campodorus rasilis Sheng, Sun \& Li sp. nov., holotype, + , habitus, lateral view (GSFGPM). 


\section{Differential diagnosis}

The new species is similar to C. ciliatus (Holmgren, 1857), but can be distinguished from the latter by the following combinations of characters: median longitudinal carinae of propodeum (Fig. 39) evenly divergent posteriorly; areas superomedia and petiolaris completely confluent. Ovipositor sheath (Fig. 41) approximately $3.5 \times$ as long as its maximum width, almost parallel. Lower lateral portion of face (Fig. 36) with large yellow spots. Hind tarsus almost entirely black. Campodorus ciliatus: median longitudinal carinae of propodeum strongly converging medially; areas superomedia and petiolaris separated by transverse carina. Ovipositor sheath $4.2 \times$ as long as maximum width, slightly expanding posteriorly. Face entirely black. At least basal halves of hind basal three tarsomeres white.

\section{Etymology}

The specific name is derived from the median area of the propodeum being smooth.

\section{Material examined}

\section{Holotype}

CHINA • +; Beijing, Yanqing; 13 Jul. 2012; interception trap; GSFGPM.

\section{Description}

\section{Female}

MEASUREMENTS. Body length approximately $8.2 \mathrm{~mm}$. Fore wing length approximately $7.1 \mathrm{~mm}$. Ovipositor sheath length approximately $0.4 \mathrm{~mm}$.

HEAD. Inner margins of eyes slightly convergent ventrally, slightly concave near antennal sockets. Face (Fig. 36) approximately $1.8 \times$ as wide as long, shagreened, upper-median portion with dense distinct punctures; upper margin with median small tubercle. Clypeus approximately $3.2 \times$ as wide as long, apical median portion distinctly convex; apical median margin distinctly concave; shiny, with very sparse punctures and brown setae. Mandible with relately sparse punctures and yellow brown setae; upper tooth same length and width as lower tooth. Malar area granulate; malar space approximately $0.4 \times$ as long as basal width of mandible. Gena and vertex (Fig. 37) shagreened. Hind portion of gena evenly convergent posteriorly. Lateral and posterior portion of vertex with fine punctures. Postocellar line approximately $0.8 \times$ as long as ocular-ocellar line. Frons shagreened, slightly concave medially. Antenna with 35 flagellomeres; ratio of length from first to fifth flagellomeres approximately: 1.7:1.2:1.0:1.0:1.0. Occipital carina complete, lower end reaching hypostomal carina distinctly above base of mandible.

Mesosoma. Anterior margin of pronotum (Fig. 38) slightly shagreened, with longitudinal fine wrinkles; upper portion of lateral concavity with distinct transverse wrinkles, lower portion with strong oblique longitudinal wrinkles; upper-posterior portion shiny, with fine punctures. Mesoscutum with dense fine punctures, distance between punctures $0.2-2.5 \times$ diameter of puncture; sparser on lateral portion, distance between punctures 1.0-4.0 $\times$ diameter of puncture. Anterior half of notauli distinctly present. Scutoscutellar groove almost shiny, lateral portion with short wrinkles. Scutellum and postscutellum with fine punctures. Postscutellum transverse. Mesopleuron (Fig. 38) with dense even punctures, distance between punctures $0.5-3.0 \times$ diameter of puncture; speculum and adjacent area smooth, shiny, without punctures. Upper end of epicnemial carina approximately reaching to 0.5 distance to subtegular ridge. Metapleuron (Fig. 38) evenly convex, with dense punctures, distance between punctures $0.5-$ $2.0 \times$ diameter of puncture; with dense short gray-brown setae. Claw simple. Ratio of length of hind tarsomeres from first to fifth approximately: 5.3:2.5:1.8:1.0:1.7. Wings gray, hyaline. Fore wing with vein $1 \mathrm{cu}-\mathrm{c}$ distal to M\&RS approximately by $0.3 \times$ length of $1 \mathrm{cu}-\mathrm{a}$. Postnervulus intercepted at lower 0.45 . Hind wing vein 1 -cu approximately $4.0 \times$ as long as cu-a. Propodeum (Fig. 39) shiny, with dense even punctures and gray white setae except smooth median longitudinal area; without transverse carinae. 

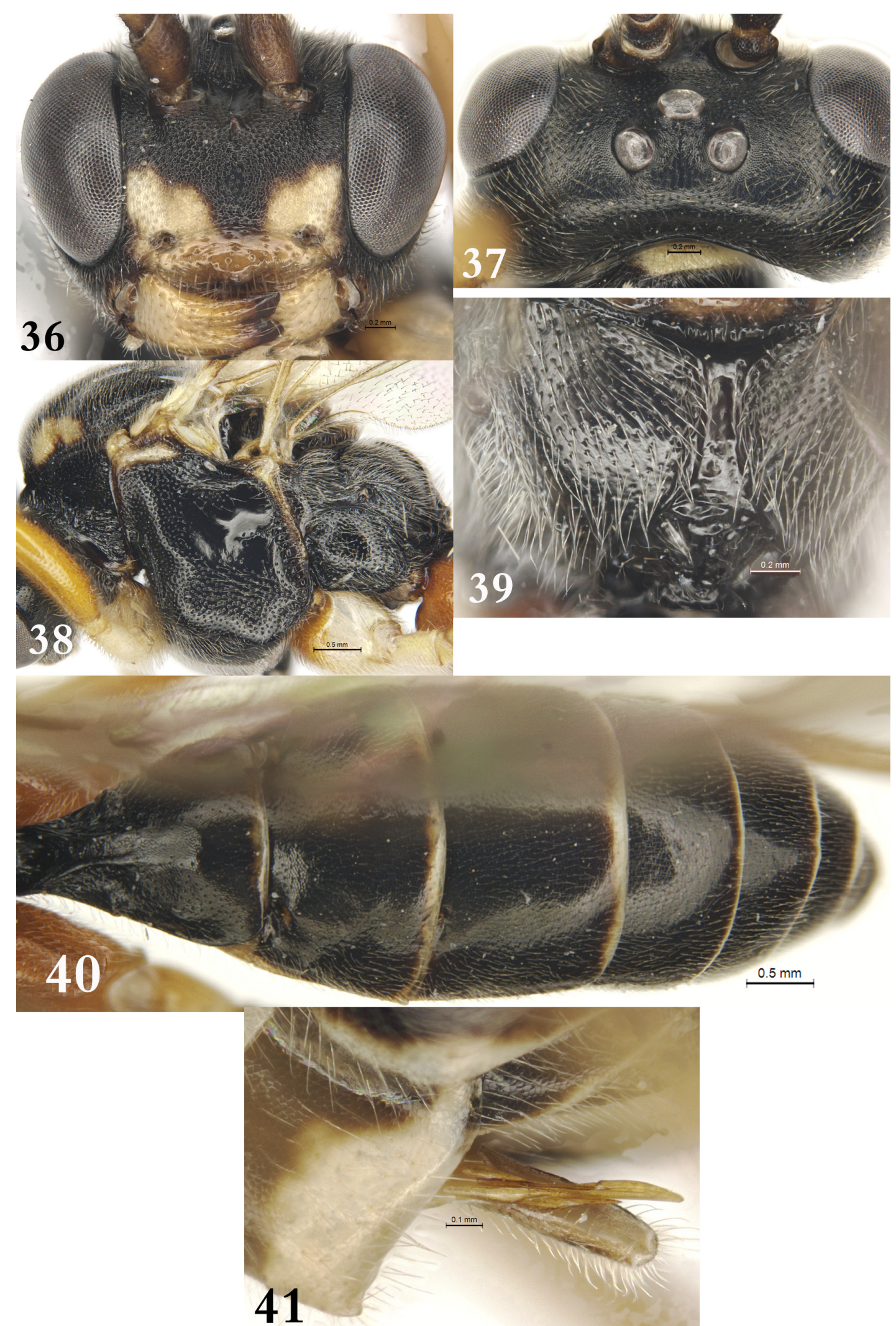

Figs 36-41. Campodorus rasilis Sheng, Sun \& Li sp. nov., holotype, q (GSFGPM). 36. Head, anterior view. 37. Head, dorsal view. 38. Mesosoma, lateral view. 39. Propodeum. 40. Metasoma, dorsal view. 41. Apical portion of metasoma, lateral view. 
Median longitudinal carinae evenly narrowed anteriorly. Area petiolaris with irregular weak wrinkles. Propodeal spiracle circular, located at anterior 0.3 of propodeum.

Metasoma. Tergites (Fig. 40) almost shiny. First tergite approximately $1.3 \times$ as long as posterior width, with sparse fine punctures; dorsal median carina reaching beyond middle; spiracle slightly convex, circular, located slightly anterior to middle of tergite. Second and subsequent tergites (Fig. 40) with fine short gray brown setae. Second tergite approximately $0.7 \times$ as long as anterior width, $0.5 \times$ as long as posterior width. Ovipositor sheath (Fig. 41) approximately $3.5 \times$ as long as its maximum width, almost parallel. Ovipositor (Fig. 41) straight.

Coloration (Fig. 35). Black, except for following: ventral profiles of scape and pedicel, flagellum brown; lower-lateral portion of face, mandible except teeth, maxillary palpi, labial palpi, fore and middle coxae mostly, all trochanters, basal half of hind tibia except basal end, upper-posterior corners of pronotum, anterolateral spots on mesoscutum, tegulae, subtegular ridge, posterior margins of tergites 1-7 yellowish white; clypeus, fore and middle femora yellowish red, tibia and first three tarsomeres whitish yellow; hind coxa red, femur red with blackish-brown apical 0.25 ; scutellum and postscutellum reddish brown; pterostigma brownish black; veins black brown. Sternites 1-3 and anterior and posterior portion of 4 yellowish white. Median portion of sternite 4 and sternites 5-6 black.

Campodorus truncatus Sheng, Sun \& Li sp. nov. urn:1sid:zoobank.org:act:CF57C494-F7D4-4EF4-9843-3FA3B0782BC8

Figs $42-51$

\section{Diagnosis}

Mesosoma coriaceous, almost without punctures. Median longitudinal carinae of propodeum (Fig. 48) strongly narrowed medially. Area petiolaris with strong median longitudinal carina. Propodeal spiracle located at anterior 0.2 of propodeum. Metasomal tergites (Figs 49-50) shagreened. Apex of ovipositor sheath (Fig. 51) truncate.

\section{Differential diagnosis}

The new species is similar to C. taigator Kasparyan, 2006, but can be distinguished from the latter by the following combinations of characters: first flagellomere $1.35 \times$ as long as second flagellomere; apex of ovipositor sheath almost truncated. Hind coxa entirely black. Basal half of hind tibia buff. Campodorus taigator: first flagellomere $1.1 \times$ as long as second flagellomere. Area superomedia absent. Apex of ovipositor sheath rounded. Hind coxa with yellowish brown spot. Basal portion of hind tibia black brown.

\section{Etymology}

The specific name is derived from the truncate apex of the ovipositor sheath.

\section{Material examined}

Holotype

CHINA • +; Liaoning Province, Xinbin; 29 May 1994; Mao-Ling Sheng leg.; GSFGPM.

\section{Paratype}

CHINA • 1 q; Liaoning Province, Xinbin; 28 May 1994; Mao-Ling Sheng leg.; GSFGPM. 

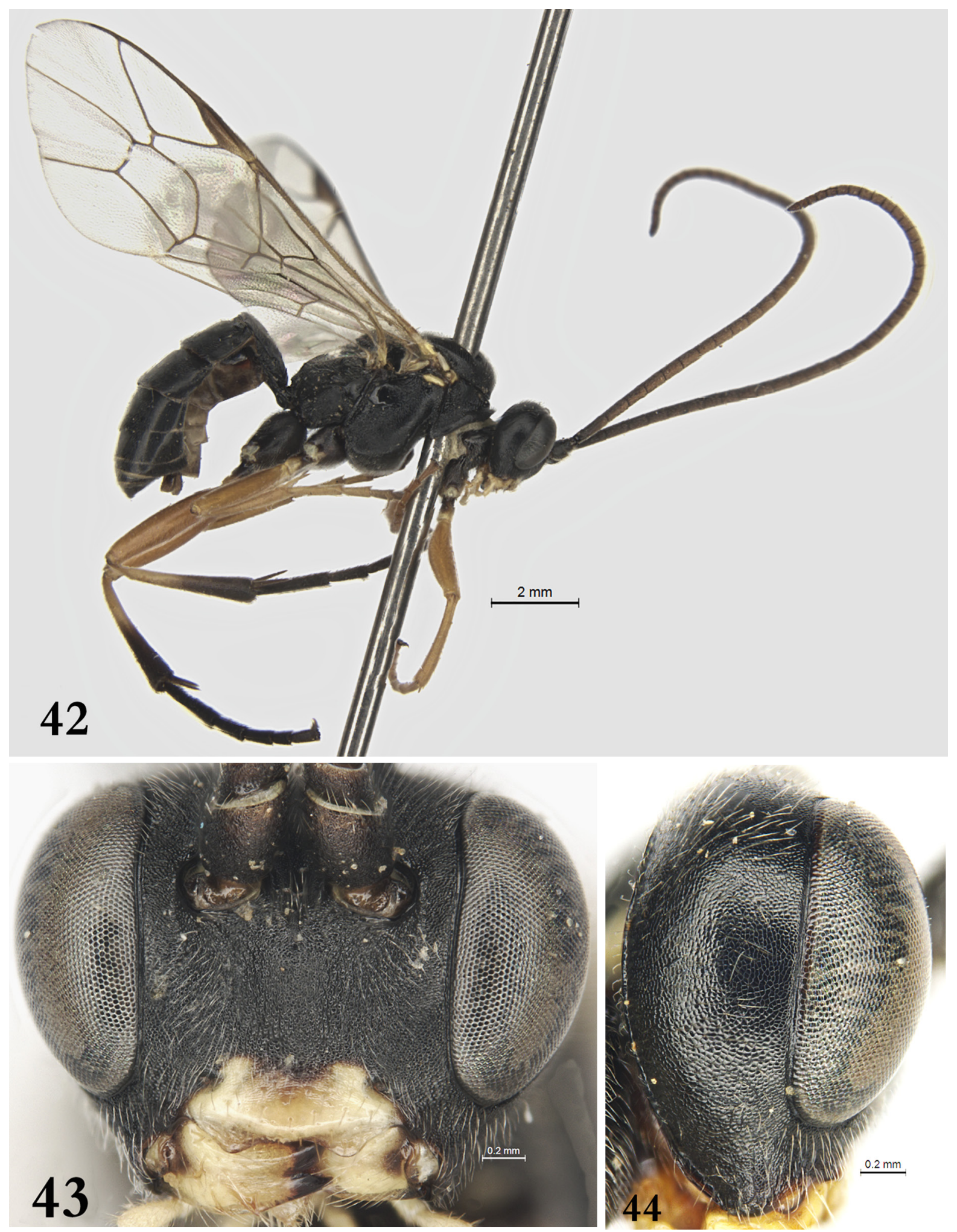

Figs 42-44. Campodorus truncatus Sheng, Sun \& Li sp. nov., holotype, $q$ (GSFGPM). 42. Habitus, lateral view. 43. Head, anterior view. 44. Head, lateral view. 


\section{Description}

\section{Female}

Measurements. Body length 7.0-7.5 mm. Fore wing length 7.0-8.0 mm. Ovipositor sheath length 0.4$0.5 \mathrm{~mm}$.

HEAD. Inner margins of eyes almost parallel. Face (Fig. 43) approximately $1.9 \times$ as wide as long, weakly convex centrally, alutaceous and coriaceous; upper margin with indistinct median small tubercle. Clypeus approximately $3.3 \times$ as wide as long, smooth, shiny, with sparse brown setae; subapical portion distinctly convex transversely; sublateral portion of apical margin triangularly convex in shape. Mandible almost shiny, with relately dense, yellow brown setae; upper tooth slightly longer than lower tooth. Malar area shagreened; malar space approximately $0.7 \times$ as long as basal width of mandible. Gena (Fig. 44), vertex (Fig. 45) and frons coriaceous. Gena wide, in dorsal view 0.9 times as long as width of eye, posterior portion convergent posteriorly. Postocellar line approximately $0.8 \times$ as long as ocular-ocellar line. Frons almost flat. Antenna with 38 flagellomeres, apical portion gradually thin apically; ratio of length from first to fifth flagellomeres approximately: 2.8:2.0:1.7:1.7:1.6. Occipital carina complete.

Mesosoma. Pronotum (Fig. 47) coriaceous; upper-anterior portion with distinct transverse wrinkles, lowermedian portion irregularly rugate. Mesoscutum (Fig. 46) finely coriaceous, lateral margin with indistinct fine punctures. Scutellum (Fig. 46), postscutellum finely coriaceous. Mesopleuron (Fig. 47) coriaceous, upper and subanterior portions with indistinct fine longitudinal rugae. Upper end of epicnemial carina approximately reaching to half height of hind margin of pronotum. Speculum smooth, shiny, without punctures. Metapleuron coriaceous, evenly convex, lower-posterior portion with indistinct wrinkles. Ratio of length of hind tarsomeres from first to fifth approximately: 5.7:3.0:2.5:1.4:2.0. Wings slightly brownish, hyaline. Fore wing with vein $1 \mathrm{cu}-\mathrm{a}$ distal to M\&RS approximately by $0.3 \times$ length of $1 \mathrm{cu}-\mathrm{a}$. Postnervulus intercepted at middle. Hind wing vein 1-cu slightly longer than cu-a. Propodeum (Fig. 48) with dense indistinct punctures, distance between punctures $0.2-1.0 \times$ diameter of puncture; median longitudinal and posterior transverse carinae complete, strong. Median longitudinal carinae strongly narrowed medially; area basalis and area superomedia confluent; area petiolaris with strong median longitudinal carina. Propodeal spiracle circular, located at anterior 0.2 of propodeum.

Metasoma. Tergites (Figs 49-50) shagreened. First tergite approximately $1.2 \times$ as long as posterior width, evenly narrowed anteriorly; dorsal median carina nearly reaching to middle; spiracle small, circular, slightly convex, located at anterior 0.4 of first tergite. Second tergite (Fig. 50) approximately $0.6 \times$ as long as apical width, with indistinct median transverse depression. Third tergite (Fig. 50) approximately $0.5 \times$ as long as apical width. Ovipositor sheath (Fig. 51) approximately $1.5 \times$ as long as its width, apex almost truncate.

Coloration (Fig. 42). Black, except for following: flagellum except basal portion, red brown ventrally, black brown dorsally; clypeus, mandible except teeth, maxillary palpi, labial palpi, tegulae, subtegular ridge, apical portions of fore and middle coxae, basal half of hind tibia except basal end, posterior margins of tergites whitish yellow; fore and middle legs except coxae, trochanters and apical parts of tarsi red brown; pterostigma and veins yellow brown. Sternites 1-3 darkish brown, 4-6 gray brown.

Campodorus variegatus (Jurine, 1807)

\section{Material examined}

CHINA • 1 q; Liaoning Prov., Xinbin; 26 Aug. 2009; interception trap; GSFGPM. 

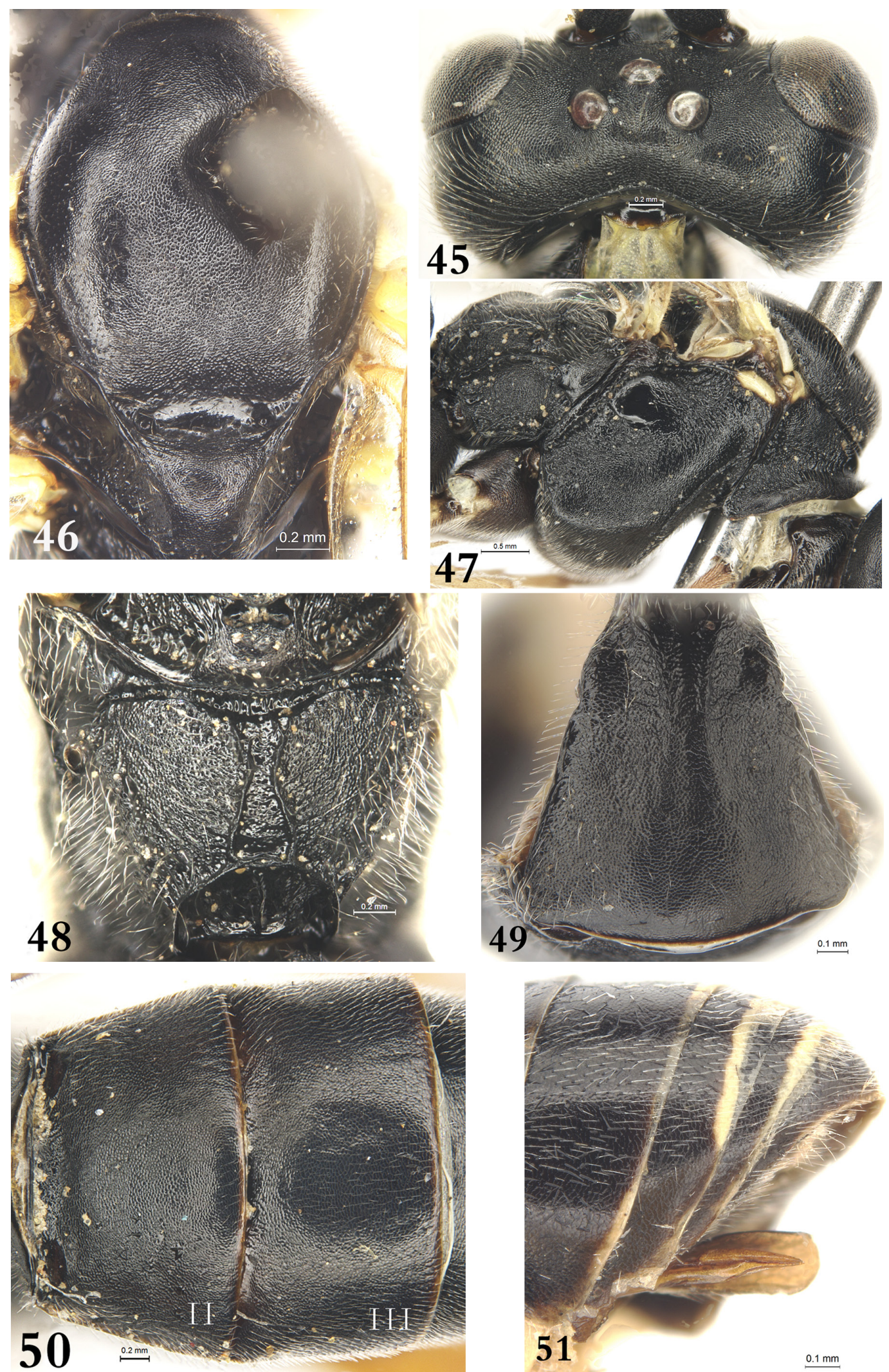

Figs 45-51. Campodorus truncatus Sheng, Sun \& Li sp. nov., holotype, + (GSFGPM). 45. Head, dorsal view. 46. Mesoscutum and scutellum. 47. Mesosoma, lateral view. 48. Propodeum. 49. Tergite 1, dorsal view. 50. Tergites $2-3$, dorsal view. 51. Apical portion of metasoma, lateral view. 


\section{Discussion}

The majority of Campodorus have been described from the Palaearctic and Nearctic Regions. Prior to this publication, only one species of Campodorus was known from the Oriental Region, from Myanmar (Kasparyan 1998), now a second species, C. albilineatus sp. nov., just described above, is known from the northern border of the Oriental part of China. Based on collections from Southern China, Guangdong, Guangxi, Fujian, Jiangxi and Yunnan Provinces, many species of Campodorus are still undescribed. The species of the Oriental Region deserve further research.

\section{Acknowledgements}

The authors are deeply grateful to Drs Dmitry R. Kasparyan (ZISP) and Gavin Broad (NHMUK) for reviewing this manuscript. The authors are also indebted to Drs Dmitry R. Kasparyan, Andrey I. Khalaim (ZISP), Gavin Broad (NHMUK), Masahiro Ohara (HUM), Stefan Schmidt and Olga Schmidt (ZSMG) for their help while the corresponding author was working in their respective collections and to Kyohei Watanabe (KPMNH) for taking some photos of type Campodorus Förster, 1869 from Japan and ZSMG. This research was supported by the National Natural Science Foundation of China (NSFC, No. 31110103062, No. 31501887) and by a key project of Science-technology basic condition platform from The Ministry of Science and Technology of the People's Republic of China (Grant No. 2005DKA21402).

\section{References}

Ashmead W.H. 1902. Papers from the Harriman Alaska Expedition XXVIII. Hymenoptera. Proceedings of the Washington Academy of Science 4: 117-268.

Broad G.R., Shaw M.R. \& Fitton M.G. 2018. Ichneumonid Wasps (Hymenoptera: Ichneumonidae): their Classification and Biology. Handbooks for the Identification of British Insects 7 (12). Royal Entomological Society, Saint Albans, UK and the Field Studies Council, Preston Montford, UK.

Carlson R.W. 1979. Family Ichneumonidae. Stephanidae. In: Krombein K.V., Hurd Jr. P.D., Smith D.R. \& Burks B.D. (eds) Catalog of Hymenoptera in America North of Mexico: 315-741. Smithsonian Institution Press, Washington.

Förster A. 1869. Synopsis der Familien und Gattungen der Ichneumonen. Verhandlungen des Naturhistorischen Vereins der Preußischen Rheinlande und Westfalens 25:135-221.

Gauld I.D., Wahl D., Bradshaw K., Hanson P. \& Ward S. 1997. The Ichneumonidae of Costa Rica, 2. Introduction and keys to species of the smaller subfamilies, Anomaloninae, Ctenopelmatinae, Diplazontinae, Lycorininae, Phrudinae, Tryphoninae (excluding Netelia) and Xoridinae, with an appendices on the Rhyssinae. Memoirs of the American Entomological Institute 57:1-485.

Heinrich G.H. 1952. Ichneumonidae from the Allgäu, Bavaria. Annals and Magazine of Natural History 12 (5): 1052-1089. https://doi.org/10.1080/00222935208654387

Jussila R. 1996. Ichneumonidae (Hymenoptera) of Greenland found in Scoresbysund (Ittoggortoormiit). Entomologica Fennica 7 (3): 145-156.

Jussila R. 2006. A new genus, four new species and a new name in Ichneumonidae (Hymenoptera) from Greenland. Entomologiske Meddelelser 74: 73-79.

Kasparyan D.R. 1998. New species of ichneumonid wasps (Hymenoptera, Ichneumonidae) collected by R. Malaise in Burma. Entomologicheskoye Obozreniye 77 (1): 216-223, 271.

Kasparyan D.R. 2001. Palaearctic ichneumonid wasps of the genus Mesoleius Holmgren (s.str) (Hymenoptera, Ichneumonidae). II. Entomologicheskoye Obozreniye 80 (3): 706-733. 
Kasparyan D.R. 2003. Palaearctic species of the ichneumonid-wasp genus Campodorus Foerster (s.str.) (Hymenoptera, Ichneumonidae) with pectinate tarsal claws. Entomologicheskoye Obozreniye 82 (3): 758-766.

Kasparyan D.R. 2005. Palaearctic species of the ichneumon-fly genus Campodorus Foerster (Hymenoptera, Ichneumonidae). II. The species with red mesothorax and the species with yellow face. Entomologicheskoye Obozreniye 84 (1): 177-195.

Kasparyan D.R. 2006. Palaearctic species of the ichneumon-fly genus Campodorus Foerster (Hymenoptera; Ichneumonidae). III. Species with long-haired ovipositor sheath, species with uniformly rufous hind tibiae, and species with white-banded tibiae. Entomologicheskoye Obozreniye 85 (3): 632661.

Kasparyan D.R. \& Khalaim A.I. 2007. Ctenopelmatinae. In: Lelej A.S. (ed.) Key to the Insects of Russia Far East. Vol. IV. Neuropteroidea, Mecoptera, Hymenoptera. Pt 5: 474-559. Dalnauka, Vladivostok. [In Russian.]

Kasparyan D.R. \& Kopelke J.-P. 2009. Taxonomic review and key to European ichneumon flies (Hymenoptera, Ichneumonidae), parasitoids of gall-forming sawflies of the genera Pontania Costa, Phyllocolpa Benson, and Euura Newman (Hymenoptera, Tenthredinidae) on willows: Part I. Entomologicheskoe Obozrenie 88 (4): 852-879.

Li T., Sheng M.-L., Sun S.-P., Chen G.-F. \& Guo Z.-H. 2012. Effect of the trap color on the capture of ichneumonids wasps (Hymenoptera). Revista Colombiana de Entomología 38 (2): 338-342.

Riedel M. \& Hansen L.O. 2012. Ichneumonidae (Hymenoptera) new for the fauna of Norway, Part 5. Norwegian Journal of Entomology 59: 219-228.

Shaw M.R. \& Kasparyan D.R. 2003. Some genera of British and European Mesoleiini (Hym., Ichneumonidae: Ctenopelmatinae) in the National Museums of Scotland, including a new species of Mesoleius and a further twenty species new to Britain. Entomologists Monthly Magazine 139 (16641666): 17-28.

Sheng M.-L. \& Sun S.-P. 2014. Ichneumonid Fauna of Liaoning. Science Press, Beijing.

Teunissen H.G.M. 1953. Anciens et nouveaux Tryphonides (Ichneumonides, Hymenopteres). Tijdschrift voor Entomologie 96: 13-49.

Thirion C., Leclercq J., Hinz R. \& Magis N. 1993. On the presence of Campodorus amictus (Holmgren, 1855) in Belgium (Hym. Ichneumonidae Scolobatinae), parasite of Pristiphora aquilegiae (Vollenhoven, 1866) (Hym. Tenthredinidae Nematinae). Bulletin et Annales de la Société royale belge d'Entomologie 129 (10-12): 291-294.

Townes H.K. 1970. The genera of Ichneumonidae, Part 3. Memoirs of the American Entomological Institute 13: 1-307.

Townes H.K. \& Townes M. 1973. A Catalogue and Reclassification of the Ethiopian Ichneumonidae. Errata for 1944-1945 Nearctic Catalogue, 1965 Eastern Palearctic Catalogue and 1966 Neotropic Catalogue. Memoirs of the American Entomological Institute 19. The American Entomological Institute, Logan UT, USA.

Uchida T. 1935. Beiträge zur Kenntnis der Ichneumonidenfauna der Kurilen. Insecta Matsumurana 9: $108-122$.

Uchida T. 1942. Ichneumoniden Mandschukuos aus dem entomologischen Museum der kaiserlichen Hokkaido Universität. Insecta Matsumurana 16: 107-146. 
Yu D.S., van Achterberg C. \& Horstmann K. 2016. Taxapad 2016, Ichneumonoidea 2015. Database on flash-drive. Nepean, Ontario.

Manuscript received: 14 November 2019

Manuscript accepted: 26 February 2019

Published on: 3 June 2020

Topic editors: Gavin Broad and Nesrine Akkari

Desk editor: Kristiaan Hoedemakers

Printed versions of all papers are also deposited in the libraries of the institutes that are members of the EJT consortium: Muséum national d'histoire naturelle, Paris, France; Meise Botanic Garden, Belgium; Royal Museum for Central Africa, Tervuren, Belgium; Royal Belgian Institute of Natural Sciences, Brussels, Belgium; Natural History Museum of Denmark, Copenhagen, Denmark; Naturalis Biodiversity Center, Leiden, the Netherlands; Museo Nacional de Ciencias Naturales-CSIC, Madrid, Spain; Real Jardín Botánico de Madrid CSIC, Spain; Zoological Research Museum Alexander Koenig, Bonn, Germany; National Museum, Prague, Czech Republic. 